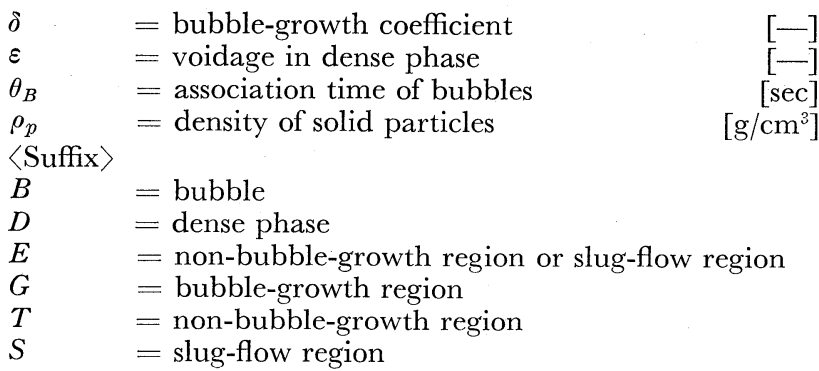

Literature Cited

1) Davidson, J. F. and D. Harrison: "Fluidised Particles", Cambridge, The Univ. Press (1963)

2) Johnstone, H. F., J. D. Batchelor and C. Y. Shen: A.I. Ch.E. Journal, 1, 318 (1955)

3) Kato, K. and C. Y. Wen: Chem. Eng. Sci., 24, 1351 (1969)

4) Kobayashi, H., F. Arai and T. Chiba: Kagaku Kōgaku (Chem. Eng., Japan), 29, 858 (1965)

5) Kobayashi, H. and F. Arai: Kagaku Kögaku (Chem.
Eng., Japan), 29, 885 (1965)

6) Kobayashi, H., F. Arai, T. Chiba and Y. Tanaka: Kagaku Kōgaku, 33, 274 (1969)

7) Kunii, D. and O. Levenspiel: "Fluidization Engineering”, p. 224, John Wiley and Sons (1968)

8) Lewis, W. K., E. R. Gilliland and W. Glass: A.I.Ch.E. Journal, 5, 419 (1959)

9) Massimilla, L. and H. F. Johnstone: Chem. Eng. Sci., 16, 105 (1961)

10) Mamuro, M. and I. Muchi: Kogyo Kagaku Zasshi, 68, 126 (1965)

11) Mori, S. and I. Muchi: Kagaku Kõgaku, 34, 510 (1970)

12) Orcutt, J. C., J. F. Davidson and R. L. Pigford: Chem. Eng. Progr. Symp. Series, 58, No. 38, 1 (1962)

13) Partridge, B. A. and P. N. Rowe: Trans. Instn. Chem. Engrs. (London), 44, 349 (1966)

14) Shen, C. Y. and H. F. Johnstone: A.I.Ch.E. Journal, 1, $349(1955)$

15) Toor, F. D. and P. H. Calderbank: "Proc. Intern. Symp. on Fluidization", Netherland Univ. Press, Amsterdam (1967)

16) Yoshida, K. and C. Y. Wen: Chem. Eng. Sci., 25, 1395 (1970)

\title{
ON A HIGH VISCOSITY POLYMER FINISHER APPARATUS WITH TWO AGITATOR AXES HAVING MULTIDISKS*
}

\author{
YASUHIRO MURAKAMI, KATSUMASA FUJIMOTO, SHIGERU \\ KAKIMOTO** AND MASAAKI SEKINO \\ Department of Chemical Engineering, Kyushu University, Fukuoka, \\ Japan
}

\begin{abstract}
The characteristics of a mixing apparatus with two agitator axes having multidisks as a high viscosity polymer finisher was studied from a practical point of view. 1) Holdup: it could be correlated by using a term of $(\mu \mathrm{nD} / \sigma)$. 2) Power consumption and mixing time: the results were compared with those of other high-viscosity equipment. 3) Residence time distribution and dead space: the former almost agreed with the tanks-inseries model. The latter seemed to be small. 4) Surface renewal action: the rate of surface renewal was determined from the gas absorption and also estimated by the observation of liquid flow.

As a model reaction polycondensation polymerization of polyamide in the presence of water and viscosity stabilizer is discussed.
\end{abstract}

\section{Introduction}

The polymer industry has charted a remarkable record of growth over the world. This paper relates

* Received on September 7, 1971

Presented in part at 3rd CHISA Congress (Sept. 1969), the 3rd Autumn Meeting (Oct. 1969), the 36th Annual Meeting (April 1971) and the Rheology Symposium (at Kanazawa, July 1971) of the Soc. of Chem. Engrs., Japan and the meeting of polymerization reaction engineering (Jan. 1971) of Soc. Poly. Sci. Japan

** Idemitsu Petroleum Chemistry Co., Ltd to the apparatus used for the production of polymeric materials, particularly of linear condensation polymers. Polycondensation is a reaction to produce a larger macromolecule by the elimination of a simple byproduct such as water, ammonia, phenol, etc.

The operation at the final stage of polycondensation is difficult because the high viscosity of the molten reaction mixture has to be dealt with. The removal of by-product in the form of bubbles requires good mixing conditions in the viscous materials.

A patent of E. I. du Pont is an example of practical application of the final finisher polymerizer ${ }^{9,12}$. 


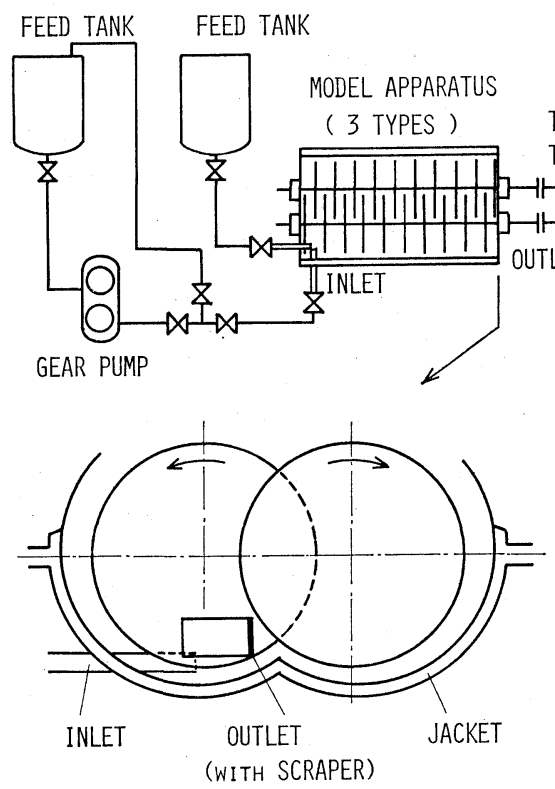

Fig. 1 Schematic diagram of experimental apparatus

It seems, however, that not many fundamental studies of continuous operation with high-viscosity liquids have been reported. The lack of this kind of information is partially due to the complexity of flow behaviour in the apparatus. Several features of transport and agitation of high-viscosity materials (about $50-5,000$ poises) are worth noting.

From a practical point of view, the most important aspects are

(1) hold-up

(2) power consumption and mixing time

(3) residence time distribution

(4) dead space (in the case where polymers may be thermally unstable or the reaction may proceed to an infusible stage)

(5) surface renewal action (removal of poly-condensation by-product)

\section{Experimental Apparatus and Procedures}

The apparatus used in this work is a du Pont type polymer finisher with two agitator axes having multidisks, as shown in Fig. 1 and Table 1. The equipment consists of two feed tanks, a feed pump (gear pump) and a jacketed vessel where the temperature of the process fluids is kept constant during mixing by passing water through the jacket.

Experimental measurements were made in the steady state condition of flow. The experiments were carried out in a controlled atmosphere. The fluids used in the experiment are aqeuous solutions of corn syrup with various concentrations (initial viscosity of about 20,000 poises), which are found to be Newtonian fluids in the range of viscosity from about 50 to 5,000 poises.

\subsection{Hold-up}

The shutdown method was applied. After the rotator was stopped and the fluid adhering to the
Table 1 Experimental condition

\begin{tabular}{lccr} 
Apparatus condition & \multicolumn{3}{c}{ unit $[\mathrm{cm}]$} \\
\hline & Type 1 & Type 2 & Type 3 \\
Disk diameter & 6 & 9 & 12 \\
Distance between axes & 4 & 6 & 8 \\
Vessel diameter & 8.4 & 11 & 14 \\
Hole diameter & 1 & 1.5 & 2 \\
\hline Distance between disks & 6.33 & 3.00 & 1.97 \\
(The number of disks) & $(5)$ & $(10)$ & $(15)$ \\
The number of holes & 0 & 4 & 20 \\
Axes length & \multicolumn{4}{c}{28.5} \\
\hline Experimental condition & \multicolumn{4}{|}{} \\
\hline Viscosity & $50-5,000$ poises \\
Rotational speed & $10-40$ & r.p.m. \\
Flow rate & $10-35$ & g/min \\
\hline
\end{tabular}

disks had settled down, the height of fluid level was measured.

\subsection{Power consumption and mixing time}

Strain gauge-type torque meters (Kyowa Electronic Instruments Co., Type TP1KMA and TP500 GMA) were used for determination of the power consumption. Variables investigated were disk diameter, rotator speed, flow rate, number of disks, width between disks, clearance between disk tip and vessel wall, viscosity and surface tension.

The mixing time was determined by the reaction between iodine and $\mathrm{Na}_{2} \mathrm{~S}_{2} \mathrm{O}_{3}$.

\subsection{Residence time distribution}

The step response method was applied. In this experiment, aqueous solution of corn syrup coloured with ink was used as the step signal tracer. The concentration of ink in outlet stream was determined by a photo-electric spectrophotometer.

\subsection{Dead space}

Dead space was obtained from residence time distribution. Here the cutoff point was $\phi=2.3$. 1.5 Surface renewal action

The degree of surface renewal action was evaluated by the gas absorption of pure $\mathrm{CO}_{2}$ in glycerine. The capacity coefficient was obtained for the batch operation by applying the surface renewal model of Danckwerts. Only liquid-phase mass transfer coefficient was considered. Experimental apparatus and flow diagram are shown in Fig. 2.

1.6 Physical properties of dispersed system of air bubbles in aqueous solution of corn syrup ${ }^{10}$ )

(a) Viscosity The viscosity of liquid in the state of the experiment was measured by a Brookfield-type viscometer at various temperatures. The temperature dependency is given by an empirical equation, Eq.(1), in spite of the existence of dispersed air bubbles.

$$
\begin{aligned}
\log \mu & =A \frac{10^{3}}{T}-B \\
A & =1.288 \log \mu_{20}+1.500 \\
B & =3.393 \log \mu_{20}+5.116
\end{aligned}
$$

(b) Density The density of the liquid including dispersed air bubbles was determined by the weighing 


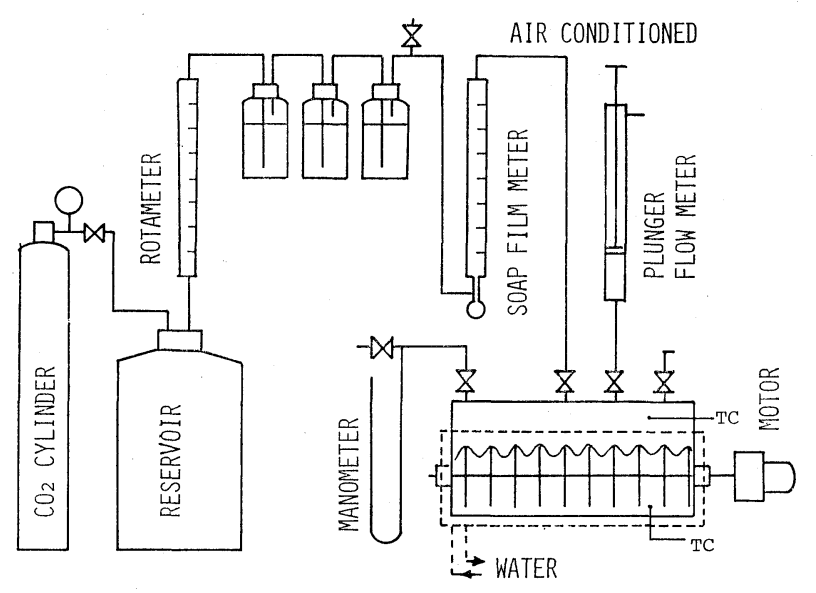

Fig. 2 Flow diagram of gas absorption experiment

method, which is similar to that for the measurement of solid density.

(c) Surface tension The measurement of surface tension of high-viscosity corn syrup aqueous solution was made by the pendant drop method ${ }^{1,3)}$ under a relative humidity of $70 \%$ to avoid the transfer of water from the droplet.

\section{Experimental Results and Discussions}

\subsection{Hold-up}

Fig. 3 shows the holding state of viscous liquid and the interesting surface profile of liquid. The theoretical prediction of the hold-up can hardly be attained because of such complicated characteristics of flow. A simplification to this system was made, assuming the similarity between a disk and a stick in the take-off action of viscous liquid.

Hirai $^{7)}$ gave the following relation for the take-off stringy length by a stick.

$$
L_{0}=3 R_{0} v \mu / \sigma
$$

where $v$ is the take-off speed.

Eq.(2) can be written in the alternate form

$$
\frac{\pi R_{0}^{2} L_{0}}{R_{0}{ }^{3}}=3 \pi \frac{v \mu}{\sigma}
$$

The following equation is assumed for the hold-up in this apparatus in a fashion similar to that of Eq.(3), regarding $\pi R_{0}^{2} L_{0}$ as a hold-up and the take-off speed $v$ as $\pi n D$.

$$
\frac{\text { Hold-up }}{D^{2} L}=K\left(\frac{\mu n D}{\sigma}\right)^{x}
$$

Experimental results can be expressed well by the dimensionless group $(\mu n D / \sigma)$ as shown in Fig. 4, from which it was obtained that $K=0.6$ and $x=1 / 7$ for Eq.(4). The hold-up in the clearance between rotating disks and vessel wall was deducted from total hold-up. It is interesting that the hold-up of high-viscosity fluid equipment is characterized by the dimensionless group $(\mu n D / \sigma)$, which is taken as a measure of judging the spinnability (stringiness) of viscous liquid.

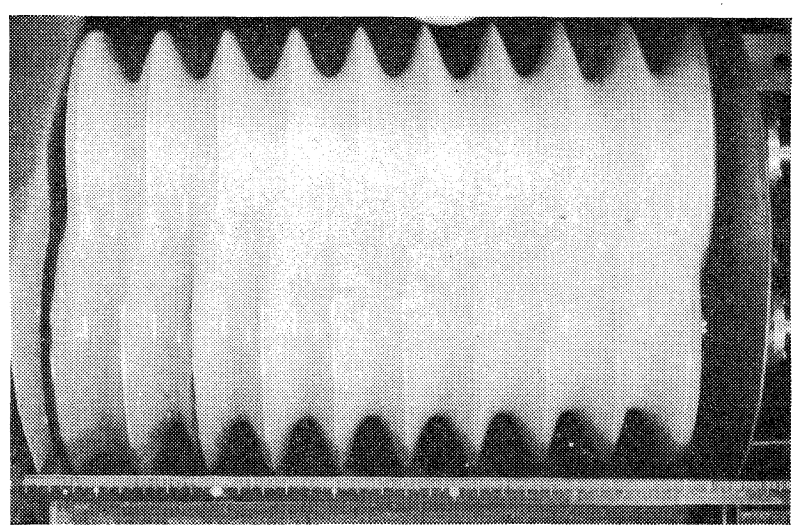

Fig. 3 Holding state of viscous liquid

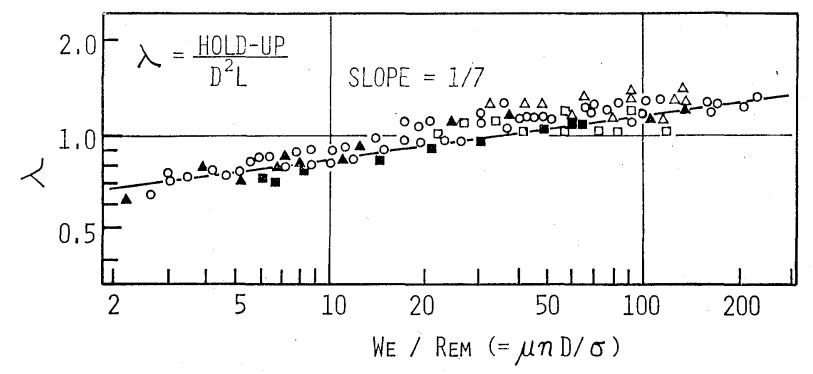

Fig. 4 Hold-up

\subsection{Power consumption and mixing time}

The power input data were correlated by plotting the power number vs. the Reynolds number and the Froude number as shown in Fig. 5, from which an empirical equation is obtained.

$$
N p=42.1 \operatorname{Re}_{M}^{-1} \mathrm{Fr}^{-0.13}(l / D)^{-1}
$$

No effect of clearance between disk tip and vessel wall on power consumption was recognized within the range of variables of this experiment.

The mean shear rate in this apparatus is estimated from Eqs. (4) and (5) as follows.

$$
\begin{aligned}
\sqrt{P_{v} g_{c} / \mu} & =8.38 n\left(\frac{n^{2} D}{g}\right)^{-1 / 15}\left(\frac{\mu n D}{\sigma}\right)^{-1 / 14}(l / D)^{-1 / 2} \\
& \simeq 10.8 n(l / D)^{-1 / 2}
\end{aligned}
$$

where $\left(n^{2} D / g\right)^{-1 / 15} \simeq 1.58$ and $(\mu n D / \sigma)^{-1 / 14} \simeq 0.818$ in the range of this experiment. If the rotating speed, $n$, is 0.5 r.p.s. and the ratio, $l / D$, is 0.3 , the mean shear rate is calculated as $\sqrt{P_{v} g_{c} / \mu} \simeq 9.86 \mathrm{sec}^{-1}$ and this value is in the same order of magnitude for the usual high viscosity mixer.

For the mixing time, the following relation was obtained experimentally regardless of the Reynolds number.

$$
n T_{M}=47(l / D)^{0.12}
$$

The relation between power consumption and mixing time is very important. From the final result of Eq. (6) and Eq. (7) the dimensionless group, $T_{M} \sqrt{P_{v} g_{c} / \mu}$, is correlated as the following equation,

$$
T_{M} \sqrt{P_{v} g_{c} / \mu}=508(l / D)^{-0.38}
$$

Table 2 shows these values in comparison with other 


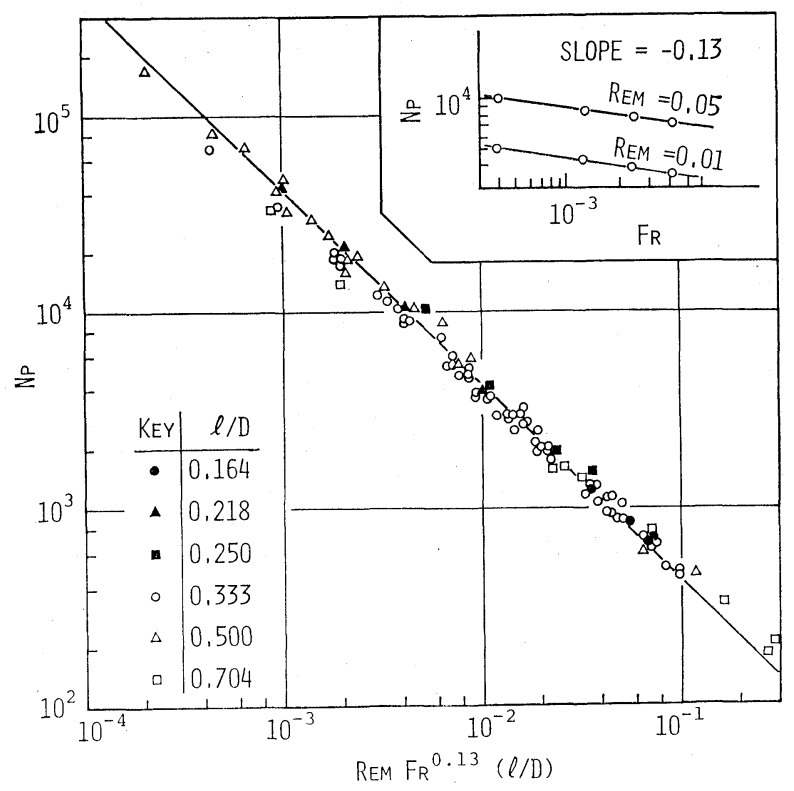

Fig. 5 Power consumption

Table 2 Mixing characteristic

Helical ribbon mixer

\begin{tabular}{ccc}
\hline worker & $n T_{M}$ & $T_{M} \sqrt{P_{v} g_{c} / \mu}$ \\
\hline Nagata et al. $^{4)}$ & 33 & 600 \\
Gray $^{9)}$ & 25.3 & 500 \\
\hline Helical screw mixer & & \\
\hline Nagata et al. $^{4)}$ & 45 & 400 \\
Gray9) & 220 & 900 \\
\hline This apparatus & & \\
\hline$l / D$ & $n T_{M}$ & $T_{M} \sqrt{P_{v} g_{c} / \mu}$ \\
\hline 0.2 & 38.7 & 940 \\
0.4 & 42.1 & 721 \\
0.6 & 44.2 & 615 \\
0.8 & 45.8 & 554 \\
\hline
\end{tabular}

type mixers ${ }^{6,11}$.

\subsection{Residence time distribution}

Fig. 6 shows one of the experimental results of $F(\dot{\phi})$-curve in which the solid and the blank points give a confirmation of reproducibility. The following relation is used in the calculation of equivalent number of perfectly mixed tanks in series.

$$
N=\left(\bar{\theta}_{T} / s\right)^{2}
$$

where $s$ is the variance obtained from the residence time distribution and $\bar{\theta}$ is the average residence time corrected by taking the dead space into consideration. Fig. 7 shows the correlation of equivalent number of perfectly mixed tanks $N$, and the experimental values are fairly scattered. In Fig. 6, the time coordinate, $\theta / \theta_{T}$, is corrected to $\theta / \bar{\theta}_{T}$. The empirical results are summarized as follows.

$$
N=4.52\left(\bar{R} e_{F} / R e_{M}\right)^{1 / 4}(l / L)^{-1}
$$

where $\bar{R} e_{F}$ and $R e_{M}$ can be understood as indicators of axial flow and radial mixing, respectively. In this experiment the operating condition for a large

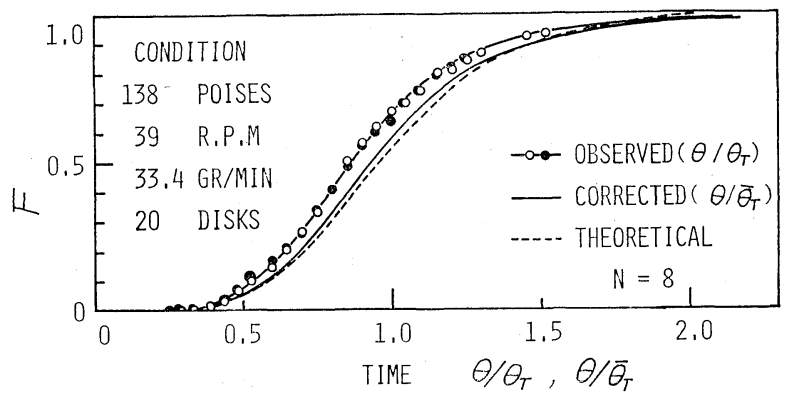

Fig. 6 An $F(\phi)$-curve

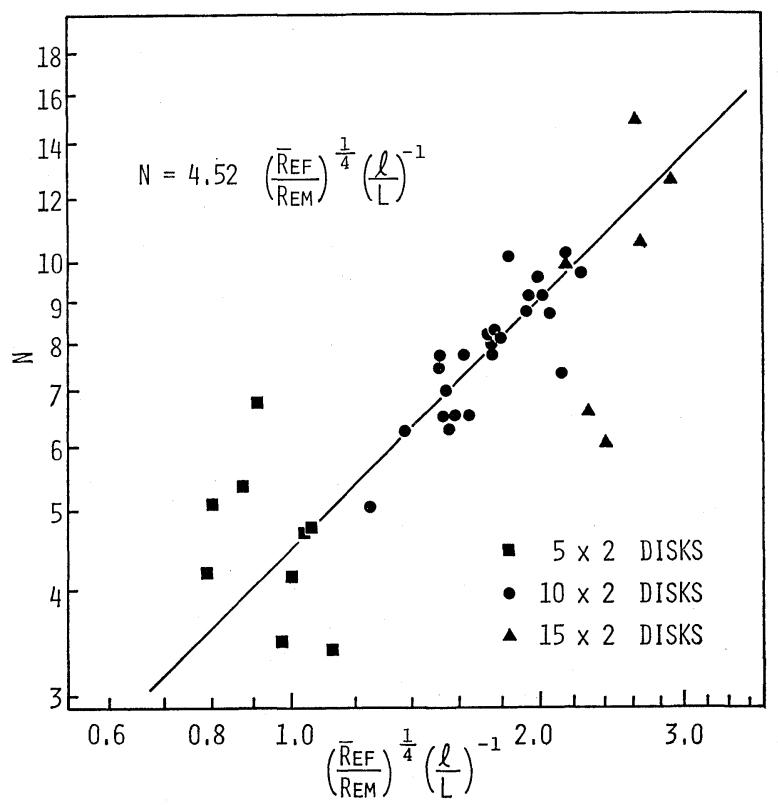

Fig. 7 Equivalent number of perfectly mixed tanks

$N$ (near plug flow) was attained easily in the case of $m=10$.

\subsection{Dead space}

The volume of dead space was obtained from the integral age distribution in which a cutoff point was $\phi=2.3$. The maximum dead space was $18 \%$ within the limit of this experiment and some results indicated $0 \%$ dead space. These values seem to be small. Although they are very scattered, the empirical equation is

$$
\theta_{T} / \bar{\theta}_{T}=1 /\left(1-V_{d} / V\right)=2.15\left(R e_{F} / R e_{M}\right)^{1 / 10}
$$

\subsection{Surface renewal action}

If the surface renewal model of Danckwerts is applied to the batch operation, the rate of absorption is expressed as

$$
N^{\prime}=V a \sqrt{D_{v} S}\left(C^{*}-C_{0}\right) \exp \left(-a \sqrt{D_{v} S} t\right)
$$

From Eq.(12) the capacity coefficient is determined by plotting $N^{\prime}$ vs. $t$ and the experimental result is as follows.

$$
k_{L} a=a \sqrt{D_{v} S}=0.58 n^{1 / 3} V^{-3 / 2}
$$

The surface area in this experiment was determined from the measurement of surface profile. 


$$
a=2.02 \times 10^{4} n^{-1 / 6} V^{-2}
$$

From these relations the rate of surface renewal $S\left[\mathrm{~cm}^{2} / \mathrm{cm}^{2} \cdot \mathrm{sec}\right]$ is given as follows.

$$
S_{\text {obs. }}=4.12 \times 10^{-3} n V
$$

where the diffusivity of $\mathrm{CO}_{2}$ in glycerine was estimated from the extrapolated data of Calderbank ${ }^{2)}$ and our experimental data by the method of stagnant liquid surface $\left(D_{v}=2.0 \times 10^{-7} \mathrm{~cm}^{2} / \mathrm{sec}\right.$ at 10.5 poises in viscosity and $20^{\circ} \mathrm{C}$ ).

The authors assume that the rate of surface renewal can be estimated by the following formula.

$$
S_{\text {est. }}=2 v_{m} L / A
$$

where $v_{m}[\mathrm{~cm} / \mathrm{sec}]$ is the average rate of surface renewal, which was determined by photographic measurement with the use of a stroboscope.

$$
v_{m}=4.2 n
$$

Accordingly, the rate of surface renewal can be estimated from Eqs.(14), (16) and (17) and the apparatus condition $L=9.5 \mathrm{~cm}$ as

$$
S_{\text {est. }}=3.95 \times 10^{-3} n^{7 / 6} \mathrm{~V}
$$

The comparison of results is shown in Fig. 8.

\section{Application to Polycondensation Polymerization Re- action of Polyamide System}

As stated in the introduction, one of the primary purposes of this study is to make a recommendation of application of this apparatus to a bulk polycondensation reaction. There are miscellaneous liquid-state polycondensations, such as nylon 66, 610, polyethylene terephthalate, polyurea and polycarbonate. An equilibrium exists in these reaction systems, and the following two reaction rate-determining steps can exsit, according to the order of the value of the equilibrium constants and permitted limit of the boundary layer thickness of the diffusion of byproduct.

1. Polycondensation reaction

2. Diffusion of byproduct molecules in the liquid state

For example, the order of a permitted limit of diffusion thickness, $\delta_{c}$, for nylon 66 can easily be considered as about $\delta_{c}=10^{-1} \sim 10^{0} \mathrm{~cm}$. When the order of boundary layer thickness is estimated by $2 \sqrt{2 D_{v} t}$ (a cut point to determine the thickness is taken as about $95 \%$ of byproduct concentration in a liquid), the required degree of surface renewal action, $S$, for nylon 66 is calculated in the following manner by assuming $D_{v} \simeq 10^{-5} \mathrm{~cm}^{2} / \mathrm{sec}$ for the order of diffusivity coefficient for byproduct.

$$
\begin{aligned}
S & =t^{-1} \simeq 8 D_{v} \delta_{c}^{-2}=8 \times 10^{-5} \times 1.0^{-2} \sim 8 \times 10^{-5} \times 0.1^{-2} \\
& =8 \times 10^{-5} \sim 8 \times 10^{-3} \mathrm{sec}^{-1}
\end{aligned}
$$

The order of the degree of surface renewal action in this experimental apparatus is larger than $S=10^{-1}$ $\mathrm{sec}^{-1}$, which shows that the rate-determining step for nylon 66 is polycondensation reaction characteristics alone. On the contrary, polyethylene terephthalate polycondensation has a very small value of equilibrium constant, about $10^{-2} \times$ (equilibrium constant for nylon 66), so that the driving force of diffu-

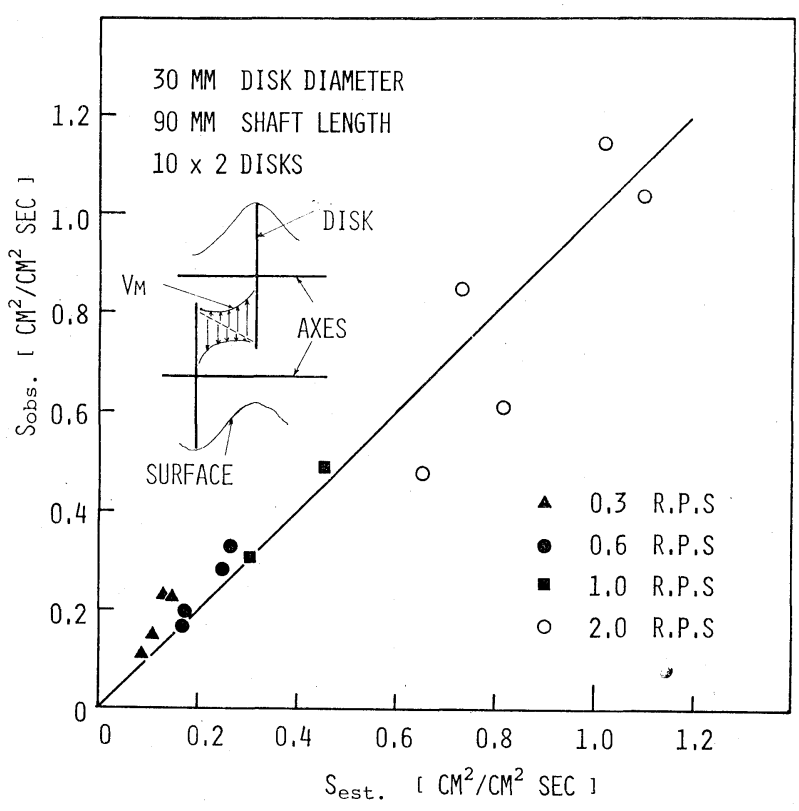

Fig. 8 The rate of surface renewal

sion is also reduced to the same order. The diffusion thickness in the case of polyethylene terephthalate polycondensation has to be $10^{-2} \times$ (the order of liquid thickness of diffusion for nylon 66), then $S=\left[8 D_{v} \delta_{c}^{-2}\right]_{\text {nylon } 66} \times 10^{4}=0.8 \sim 80 \mathrm{sec}^{-1}$, which value suggests that the rate-determining step for polyethylene terephthalate condensation is diffusion of byproduct in the liquid state. From the above-mentioned discussion, engineering considerations for nylon 66 are restricted to the problem concerned with completion of the reaction.

The polycondensation reaction of nylon salt is expressed by the following formula.

$$
\begin{gathered}
-\mathrm{COOH}+-\mathrm{NH}_{2} \underset{k_{2}}{\stackrel{k_{1}}{\rightleftarrows}}-\mathrm{NHCO}-+\mathrm{H}_{2} \mathrm{O} \\
K=k_{1} / k_{2},
\end{gathered}
$$

The amount of water in the system has a large effect on reaction rate and degree of polymerization. When a monobasic acid such as acetic acid is used as a viscosity stabilizer, the following relation is expected to be valid.

$$
-\frac{d[\mathrm{COOH}]}{d t}=k_{1}[\mathrm{COOH}]\left[\mathrm{NH}_{2}\right]-k_{2}[\mathrm{NHCO}] n_{w}
$$

Kinetic studies of polycondensation of nylon salt in the presence of water and viscosity stabilizer are not sufficiently extensive.

$$
\alpha Q=a+b
$$

where $\alpha Q$ is the net molecule of the stabilizer, $b$ is the molecule of the stabilizer used in reaction and $a$ is the free molecule of the stabilizer in the polymerization system.

If the conversion of monomer is $100 \%$,

$$
\begin{aligned}
& {[\mathrm{P}-\mathrm{COOH}]=1 / P n} \\
& {[\mathrm{~S}-\mathrm{COOH}]=a+\alpha Q-b} \\
& {\left[\mathrm{NH}_{2}\right]=1 / P n-b} \\
& {[\mathrm{NHCO}]=2-1 / P n+b}
\end{aligned}
$$




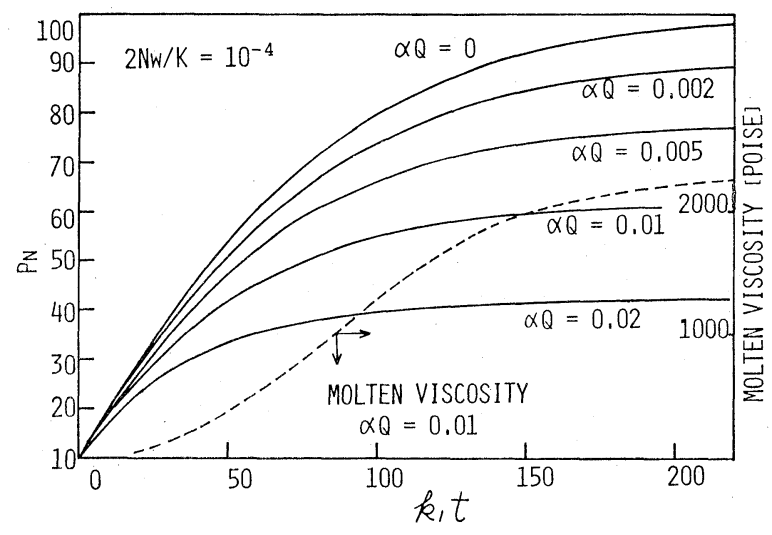

Fig. 9 Effect of viscosity stabilizer

where $\mathrm{S}-\mathrm{COOH}$ is the molecule of stabilizer, and $\mathrm{P}-\mathrm{COOH}$ is the molecule of $\mathrm{COOH}$ end groups in polymer.

Assumptions :

(1) The reactivity of $\mathrm{S}-\mathrm{COOH}$ equals that of $\mathrm{P}-$ $\mathrm{COOH}$.

(2) The reaction rate of $\mathrm{S}-\mathrm{COOH}$ and $\mathrm{P}-\mathrm{COOH}$ is proportional to the concentration of $\mathrm{S}-\mathrm{COOH}$ and $\mathrm{P}-\mathrm{COOH}$ in batch or plug-flow operation respectively; that is,

$$
-\frac{d[\mathrm{~S}-\mathrm{COOH}]}{d[\mathrm{P}-\mathrm{COOH}]}=\frac{[\mathrm{S}-\mathrm{COOH}]}{[\mathrm{P}-\mathrm{COOH}]}
$$

If the degree of polymerization is equal to $1 / 2$ at the time of adding the stabilizer, then

$$
[\mathrm{S}-\mathrm{COOH}]=\alpha Q[\mathrm{P}-\mathrm{COOH}] / 2
$$

Therefore, from Eq.(22)

$$
\begin{aligned}
{[\mathrm{COOH}] } & =[\mathrm{P}-\mathrm{COOH}]+[\mathrm{S}-\mathrm{COOH}] \\
& =(1+\alpha Q / 2) / P n \\
{\left[\mathrm{NH}_{2}\right] } & =(1+\alpha Q / 2) / P n-\alpha Q \\
{[\mathrm{NHCO}] } & =2+\alpha Q-(1+\alpha Q / 2) / P n
\end{aligned}
$$

From Eqs. (20) and (25),

$$
\frac{d P n}{d t}=k_{1}\left[\left(1+\frac{\alpha Q}{2}\right)+\left(\frac{n_{w}}{K}-\alpha Q\right) P n-\frac{2 n_{w}}{K} P n^{2}\right]
$$

Equilibrium value $P n_{\infty}(d P n / d t=0)$ from Eq.(26) agrees fairly well with Fukumoto's result ${ }^{5)}$ in practical conditions as $1 \gg \alpha Q / 2$ and $\alpha Q \gg n_{w} / K$.

In the case of $n_{w} / K$ being a constant, which is a reasonable assumption under the condition of low water content at the stage of final polymerization, the above equation, Eq.(26), can be solved analytically as follows.

$$
\begin{aligned}
& \frac{P n-X}{P n+Y}=\frac{P n o-X}{P n o+Y} \exp \left(-k_{1} \xi t\right) \\
& \xi^{2}=\left(n_{w} / K-\alpha Q\right)+4 n_{w}(2+\alpha Q) / K \\
& X=2(1+\alpha Q / 2) /\left[\xi-\left(n_{w} / K-\alpha Q\right)\right] \\
& Y=2(1+\alpha Q / 2) /\left[\xi+\left(n_{w} / K-\alpha Q\right)\right] \\
& P n=P n o \text { at } t=0
\end{aligned}
$$

Fig. 9 shows the effect of stabilizer on the degree of polymerization and molten viscosity.

The authors will briefly describe the process of estimation of the molten viscosity. For nylon 6

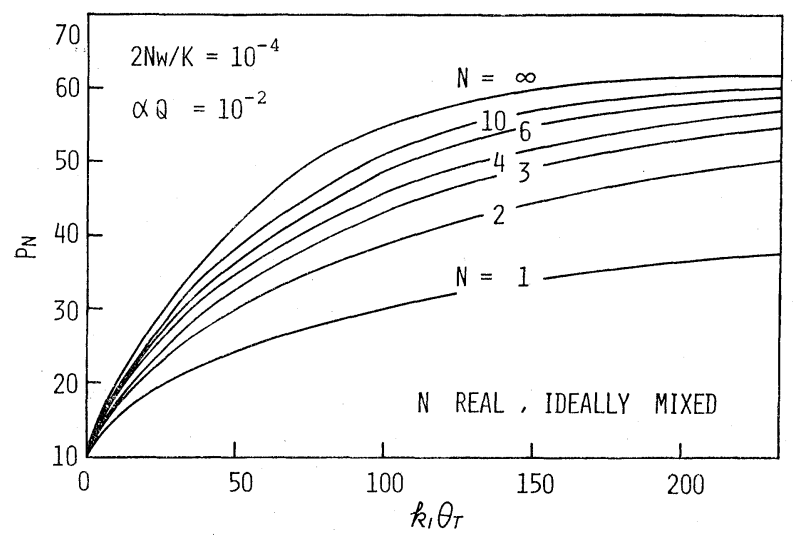

Fig. 10 Effect of the number of perfectly mixed tanks

Hoshino $^{8)}$ gives

$$
\log \mu=-7.0+\frac{2300}{T}+6.2[\eta]_{m \text {-cresol }}^{0.5}
$$

The relation between intrinsic viscosity and degree of polymerization for nylon 6 is reported by Fukumoto $^{4)}$ as

$$
\bar{P} n=127.4[\eta]_{m \text {-cresol }}^{1.435}
$$

Considering the structural unit of nylon 6 and nylon 66 , the relation $\bar{P} n=2 P n$ may be correct, and Eqs.(28) and (29) for nylon 6 may thus be made available for nylon 66. Therefore the molten viscosity can be estimated in the apparatus by the following equation.

$$
\log \mu=-7.0+\frac{2300}{T}+1.146(2 P n)^{0.349}
$$

For a perfectly mixed continuous tank reactor the following relation is derived from mass balance considerations with respect to the end-group in the steadystate condition.

$$
[\mathrm{COOH}]_{\mathrm{in}}-[\mathrm{COOH}]=\theta_{T} r_{\mathrm{COOH}}
$$

Using the expression $[\mathrm{COOH}]_{i n}=[\mathrm{COOH}]_{N-1}=$ $X_{N-1}$ and Eqs.(25), (26) and (31), the following relation is obtained for the $N$-th tank.

$$
\begin{gathered}
(P n)_{N}=\frac{\alpha_{2}}{2\left(\frac{X_{N-1}}{k_{1} \theta_{T}}+\frac{2 n_{w}}{K}\right)}\left[-\left(\alpha_{1}-\frac{1}{k_{1} \theta_{T}}-\frac{n_{w}}{K}\right)\right. \\
+\sqrt{\left.\left(\alpha_{1}-\frac{1}{k_{1} \theta_{T}}-\frac{n_{w}}{K}\right)+4\left(\frac{X_{N-1}}{k_{1} \theta_{T}}+\frac{2 n_{w}}{K}\right)\right]} \\
\text { where } \begin{array}{c}
X_{N-1}=\alpha_{2} /(P n)_{N-1} \\
\alpha_{1}=\alpha Q \text { and } \alpha_{2}=1+\alpha Q / 2
\end{array}
\end{gathered}
$$

The resultant degree of polymerization is shown in Fig. 10. This shows that the number of tanks-inseries should be greater than $N=10$ for the polyamide polycondensation polymerization system. The authors show here a method to realize equivalent number of perfectly mixed tanks in series, $N$, in connection with Eq.(10). Generally speaking, the order of average transport speed, $\bar{U}$, of process fluid may be taken as $\bar{U}=0.5 \mathrm{~m} / \mathrm{hr}$ in such a reactor for high-viscosity fluid. Length of the apparatus, $L$, is determined by using $\bar{U}$ and reaction time. The ratio of $l / D=0.3$ is sound in view of the geometrical 
structure. $R e_{M}$ must be checked on the basis of power consumption (practically $<10^{2} \mathrm{kw} / \mathrm{m}^{3}$ process fluid, $n<10^{2}$ r.p.m.). The calculation processes to design the apparatus are summarized in the following diagram.

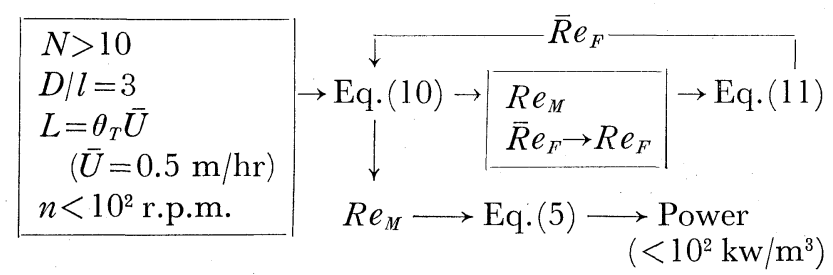

The condition of $2 n_{w} / K=10^{-4}$ was used in the numerical calculation. This condition seems to be allowable by considering the equilibrium degree of polymerization $P n_{\infty}$.

$$
P n_{\infty}=\sqrt{K / 2 n_{w}}=100
$$

\section{Conclusions}

1. The hold-up is estimated fairly well by using only a dimensionless term ( $\mu n D / \sigma)$, as shown in Eq.(4).

2 . The power requirement for agitation of highviscosity fluid can be calculated from Eq.(5). The relation between power consumption and mixing time is also discussed revealing the similarity to double helical ribbon mixer.

3. The equivalent number of perfectly mixed tanks based on the tanks-in-series model can be estimated by Eq.(10) and seems to be near that for plug flow.

4. The fraction of dead space in this apparatus seems to be small and is correlated by Eq.(11), although the experimental values are very scattered.

5. Surface renewal action is discussed and the rate of surface renewal is correlated and estimated as Eqs.(15) and (16), respectively.

6. The kinetics of nylon salt polymerization is investigated in the presence of a monobasic acid as a viscosity stabilizer. The authors use Eq.(26) to estimate the conditions required for continuous operation of this apparatus.

\section{Acknowledgement}

In preparing this presentation, the authors wish to express their gratitude to Prof. Y. Sato and Dr. T. Hirose for their frequent and helpful discussions, also to Messrs. M. Takao, A. Yoshida, Y. Moriyama, K. Asano and H. Yoshida for their assistance throughout the experimental programme.

The authors are grateful to the Scientific Research Fund of the Ministry of Education and for financial help to Mitsubishi Heavy Ind. Ltd., Hiroshima Laboratory.

\section{Nomenclature}

$$
\begin{array}{llr}
A & =\text { surface area of liquid } & {\left[\mathrm{cm}^{2}\right]} \\
a & =\text { that per unit volume } & {\left[\mathrm{cm}^{2} / \mathrm{cm}^{3}\right]} \\
C^{*} & =\text { equilibrium concentration of } \mathrm{CO}_{2} \text { in liquid } & {\left[\mathrm{cm}^{3} / \mathrm{cm}^{3}\right]} \\
C_{0} & =\text { initial concentration of } \mathrm{CO}_{2} \text { in liquid } & \\
& & {\left[\mathrm{cm}^{3} / \mathrm{cm}^{3}\right]}
\end{array}
$$

$D \quad=$ disk diameter

$D_{v}=$ diffusivity in liquid phase of $\mathrm{CO}_{2}$

$K=$ equilibrium constant

$k_{1}, k_{2}=$ rate constants

[AHmole $/ \mathrm{mole} \cdot \mathrm{hr}]$

$L \quad=$ axes length

$L_{0} \quad=$ liquid stringy length

$l=$ distance between disks

$m=$ the number of disks for an axis

$N=$ the number of perfectly mixed tanks

$N^{\prime} \quad=$ gas absorption rate

$n \quad=$ rotational speed

$n_{w}=$ the amount of water

$P \quad=$ power consumption

$P_{v}=$ that per unit volume

$P n,(P n)_{N}, P n o, P n_{\infty}=$ the degree of polymerization of nylon 66 , that for $N$-th tank, that at $t=0$ and that at $t=\infty$, respectively

$\bar{P} n \quad=$ the degree of polymerization of nylon 6

$R_{0} \quad=$ radius of liquid string

$r_{\mathrm{COOH}}=$ reaction rate of $\mathrm{COOH}$

$[\mathrm{mole} / \mathrm{AHm}]$

$S, S_{0, S} S_{\text {[mole/AHmole.hr] }}$ observed and that estimated, respectively $\quad\left[\mathrm{cm}^{2} / \mathrm{cm}^{2} \cdot \mathrm{sec}\right]$

$\begin{array}{ll}s & =\text { variance } \\ T & =\text { absolute temperature }\end{array}$

$T_{M} \quad=$ mixing time

$T_{M}=$ mixing time $\quad[\mathrm{Kec}]$

$t_{\bar{U}}^{t}=$ reaction time and absorption time [hr, sec]

$\bar{U} \quad=$ average transport speed of process fluid

$V, V_{d}=$ liquid volume and dead space, respectively $[\mathrm{m} / \mathrm{hr}]$

$v \quad=$ take-off speed of liquid string $\left[\mathrm{cm}^{3}\right]$

$\begin{array}{lll}v & =\text { take-off speed of liquid string } & {[\mathrm{cm} / \mathrm{sec}]} \\ v_{m} & =\text { average velocity of liquid at surface } & {[\mathrm{cm} / \mathrm{sec}]}\end{array}$

$\alpha Q=$ the amount of stabilizer in system

$\delta c \quad=$ diffusion thickness

$[\eta] \quad=$ intrinsic viscosity

$\mu, \mu_{20}=$ liquid viscosity and that at $20^{\circ} \mathrm{C}$ respectively

$\sigma \quad=$ surface tension

$\theta_{T} \quad=$ space time

$\bar{\theta}_{T} \quad=$ residence time

Fr $\quad=$ Froude number $=n^{2} D / g$

$N p \quad=$ power number $=P g_{c} / \rho n^{3} D^{4} L$

$\operatorname{Re}_{F} \quad=$ axial flow Reynolds number $=\rho D L \mid \mu \theta_{T}$

$\bar{R} e_{F}=$ axial flow Reynolds number $=\rho D L / \mu \bar{\theta}_{T}$

$R e_{M}=$ mixing Reynolds number $=\rho n D^{2} / \mu$

$\left.\mu n D\right|_{\sigma}=$ capillary number $=W e / R e_{M}$

\section{Literature Cited}

1) Andreas, J. M.: J. Phys. Chem., 42, 1001 (1938)

2) Calderbank, P. H.: Trans. Inst. Chem. Eng., 37, 173 (1959)

3) Fordham, S.: Proc. Roy. Soc. (London), A 194, 1 (1948)

4) Fukumoto, O.: J. Polymer Sci., 22, 263 (1956)

5) Fukumoto, O.: Kobunshi Kagaku, 18, 22 (1961)

6) Gray, J. B.: Chem. Eng. Progr., 59, 55 (1963)

7) Hirai, N.: Chem. Soc. (Japan), 75, 1019 (1954)

8) Hoshino, K.: Chem. Soc. (Japan), 65, 419 (1944)

9) Ichikawa, Y.: Kagaku Kōgaku (Chem. Eng., Japan), 24, 940 (1960)

10) Murakami, Y., M. Takao and K. Fujimoto: Technology Reports of the Kyushu University, 44, 94 (1971)

11) Nagata, S., T. Yanagimoto and T. Yokoyama: Kagaku Kōgaku (Chem. Eng., Japan), 21, 278 (1957)

12) Vodnik, J. L.: U.S.P. 2,758,915 (du Pont). 